\title{
Carbon-Carbon Aeroshell Chemical Reaction Model in an Open RPS in Martian Environment
}

\section{September 2020}

Brad L. Kirkwood

Idaho National Lab; Space Nuclear Power \& Isotope Technologies

Christofer E. Whiting

University of Dayton Research Institute; Power \& Energy Division

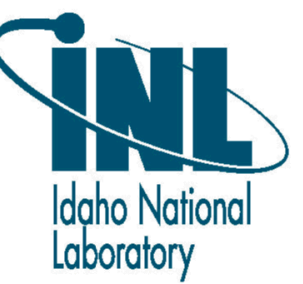




\section{DISCLAIMER}

This information was prepared as an account of work sponsored by an agency of the U.S. Government. Neither the U.S. Government nor any agency thereof, nor any of their employees, makes any warranty, expressed or implied, or assumes any legal liability or responsibility for the accuracy, completeness, or usefulness, of any information, apparatus, product, or process disclosed, or represents that its use would not infringe privately owned rights. References herein to any specific commercial product, process, or service by trade name, trade mark, manufacturer, or otherwise, does not necessarily constitute or imply its endorsement, recommendation, or favoring by the U.S. Government or any agency thereof. The views and opinions of authors expressed herein do not necessarily state or reflect those of the U.S. Government or any agency theof. 
INL/EXT-20-59457

Revision 1

\title{
Carbon-Carbon Aeroshell Chemical Reaction Model in an Open RPS in Martian Environment
}

\author{
Brad L. Kirkwood \\ Idaho National Lab; Space Nuclear Power \& Isotope Technologies \\ Christofer E. Whiting \\ University of Dayton Research Institute; Power \& Energy Division
}

September 2020

Idaho National Laboratory

Space Nuclear Power and Isotope Technologies

Idaho Falls, Idaho 83415

http://www.inl.gov

Prepared for the

U.S. Department of Energy

Office of Nuclear Energy

Under DOE Idaho Operations Office

Contract DE-AC07-05ID14517 
Page intentionally left blank 


\begin{abstract}
A new RPS is being designed to be open to the vacuum of space to improve its thermal efficiency during deep space missions. This design, however, could lead to some potential complications if it is ever used in the low-pressure gas environment of mission destinations like Mars. This report documents the development of a chemical kinetics reaction model of the FWPF carboncarbon aeroshell in the Martian gaseous environment. This model uses an "infinite sink" assumption where the RPS is open to the Martian environment with open exchange of flowing gases, so the gas chemistry over the aeroshell does not change with the reaction and represents the worst case scenario of the chemical reaction of the FWPF in the Martian environment.

The model combines the kinetics equation of both oxidation reactions that would occur on Mars: the Langmuir-Hinshelwood kinetics of the Boudouard reaction of $\mathrm{CO}_{2}$ with the chemical kinetics of $\mathrm{O}_{2}$ oxidation of the carbon-carbon. The FWPF chemical reaction model was benchmarked using the Opila's experimental chemical reaction test data (1) in a simulated Martian environment to increase the validity of the model's predicted mass loss rate. The output of the benchmarked chemical reaction model showed a trade-off between the maximum temperature of the aeroshell to have less than $10 \%$ reaction at the mission life. For example, an RPS with a five-year intended mission life on Mars has a maximum aeroshell temperature of $835 \mathrm{~K} / 562{ }^{\circ} \mathrm{C}$, increasing the mission life to ten years reduces the maximum operating temperature to $810 \mathrm{~K} / 527^{\circ} \mathrm{C}$. If the aeroshell operating temperature in the new RPS on the surface of Mars is 960 Kelvin, the model calculates that the life is limited to 0.22 years / 81 days. Increasing the aeroshell temperature to $1343 \mathrm{Kelvin}$, further reduces the life to 0.375 days / 9 hrs. This illustrates the thermally activated nature of the chemical kinetics model in limiting the life of the aeroshell.
\end{abstract}


Page intentionally left blank 


\section{CONTENTS}

ABSTRACT, SUMMARY, FOREWORD, AND ACKNOWLEDGEMENTS..........................................ii

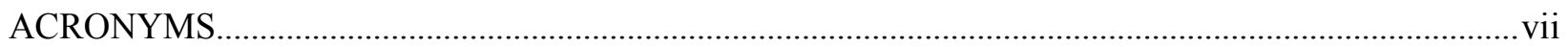

1. Carbon-Carbon Aeroshell Reaction Model for an Open RPS in Martian Environment........................1

1.1 Development of Chemical Reaction Kinetics Model for FWPF Carbon-Carbon..................... 1

1.2 Benchmarking of FWPF Chemical Reaction Kinetics Model in Martian Environment...........5

1.3 Calculation of Degree of Reaction of FWPF Aeroshell with Chemical Reaction Kinetics

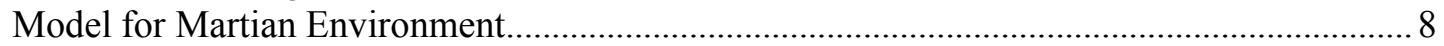

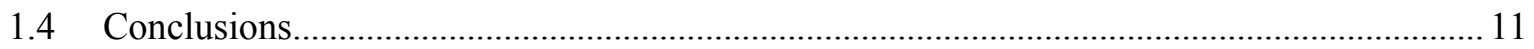

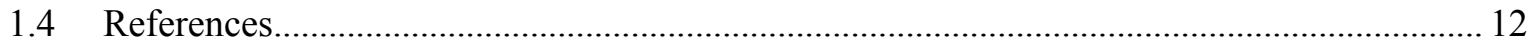

\section{FIGURES}

Figure 1 Arrenhius Plot of the Oxidation of Uninhibited Carbon- Carbon at 0.21 atm Oxygen Partial

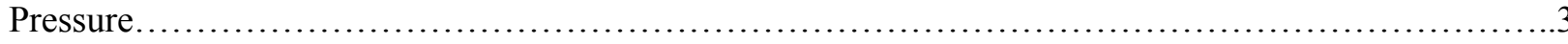

Figure 2 Comparison of the FWPF Reaction Model with "Best Fit" Parameters to Opila Experimental

Reaction Weight Loss Data at $900{ }^{\circ} \mathrm{C}$ and $800 \mathrm{~Pa} \mathrm{CO}_{2}$ and $0.8 \mathrm{~Pa} \mathrm{O}_{2}$ Partial Pressures (Simulating a Martian Environment).

Figure 3a Predicted Degrees of Reaction from Benchmarked FWPF Reaction Model at Temperatures from $300{ }^{\circ} \mathrm{C}$ to $900{ }^{\circ} \mathrm{C}$ at $763 \mathrm{~Pa} \mathrm{CO}_{2}, 1.04 \mathrm{~Pa} \mathrm{O}_{2}$ and 0.64 $\mathrm{PaCO}$ Partial Pressures, Simulating a Martian Environment; Semi-logarithmic Plot.

Figure $3 \mathrm{~b}$ Predicted Degrees of Reaction from the Benchmarked FWPF Reaction Model at Temperatures from $300{ }^{\circ} \mathrm{C}$ to $900{ }^{\circ} \mathrm{C}$ at $763 \mathrm{~Pa} \mathrm{CO}_{2}, 1.04 \mathrm{~Pa} \mathrm{O}_{2}$ and 0.64 $\mathrm{PaCO}$ Partial Pressures, Simulating a Martian Environment; Log-Log Plot.

Figure 4 Predicted FWPF Degrees of Reaction from the Benchmarked FWPF Reaction Model at Martian Mission Lives from 0.05 to 10 years as a Function of Aeroshell Temperature in a Martian

Environment.

Figure 5 GPHS FWPF Aeroshell Upper Temperature Limits as a Function of the Intended Mission Life of an RPS Open to the Martian Environment

\section{TABLES}

Table I Hustad and Barrio Boudouard Reaction Rate Kinetics Constants and Langmuir-Hinshelwood Coefficients

Table II "Best Fit" Calibration Parameters for the GPHS FWPF Reaction Model to Fit Opila Experimental Reaction Weight Loss Data at $900{ }^{\circ} \mathrm{C}$ with $800 \mathrm{~Pa} \mathrm{CO}_{2}$ and $0.8 \mathrm{~Pa} \mathrm{O}_{2}$ Partial Pressures....7

Table III GPHS FWPF Aeroshell Upper Temperature Limits as a Function of the Mission Life of an RPS Open to the Martian Environment 
Page intentionally left blank 


\section{ACRONYMS}

FWPF Fine Weave Pierced Fabric

$\mathrm{C} / \mathrm{C} \quad$ Carbon - Carbon Composite Material

RPS Radioisotope Power System

MMRTG Multi-Mission Radioisotope Thermoelectric Generator

GPHS-RTG General Purpose Heat Source- Radioisotope Thermoelectric Generator 
Page intentionally left blank 


\section{Carbon-Carbon Aeroshell Chemical Reaction Model for an Open RPS in Martian Environment}

\subsection{Development of a Chemical Reaction Kinetics Model for FWPF Carbon-Carbon}

A new RPS is being designed to be open to the vacuum of space to improve its thermal efficiency during deep space missions. This design, however, could lead to some potential complications if it is ever used in the low-pressure gas environment of mission destinations like Mars. Mission destinations with atmospheres are not the primary concern of this RPS design.

A chemical reaction kinetics model has been developed to calculate the amount of chemical reaction that Fine Weave Pierced Fabric Carbon - Carbon GPHS aeroshell would experience during its operational life on Mars in this new RPS. The model uses the carbon dioxide, carbon monoxide and oxygen partial pressures in the Martian atmosphere in chemical kinetics models to calculate the total amount of chemical reaction. While the partial pressure of $760 \mathrm{~Pa} \mathrm{CO}_{2}$ partial pressure predominates in the Martian environment and drives the Boudouard Reaction, the small 1.04 Pa partial pressure of molecular oxygen, $\mathrm{O}_{2}$ has been shown in an experimental study by Opila (1) to dominate the total chemical reaction under these pressure conditions. The chemical reaction model developed in this report combines the reaction rate kinetics of the Boudouard reaction with the kinetics of $\mathrm{O}_{2}$ oxidation reaction of the carbon - carbon aeroshell based upon the experimental observations of the Opila report.

The chemical reaction model developed in this report is for an RPS which is open to the Martian environment with open exchange of flowing gases, so the gas chemistry over the aeroshell does not change with the reaction. This "infinite sink" assumption is appropriate for an open RPS and would be the worst case scenario of chemical reaction with the Martian environment. In a closed or semi closed environment, the $\mathrm{O}_{2}$ and $\mathrm{CO}_{2}$ over the aeroshell would quickly be depleted and converted through reaction to $\mathrm{CO}$. The rates of these oxidation reactions would drop to zero. The rate of chemical reaction of the aeroshell in a "closed" scenario would be controlled by the leak rates of $\mathrm{O}_{2}, \mathrm{CO}$ and $\mathrm{CO}_{2}$ gases, not by their chemical kinetics and significantly slower.

The Boudouard reaction of $\mathrm{CO} 2$ with carbon was modelled using the Langmuir-Hinshelwood kinetics equation as shown in Equations 1 and 2 (2). This use of this kinetics equation includes the effects of the partial pressure of both carbon monoxide and carbon dioxide in the calculation of the reaction rate.

Eqn. 1

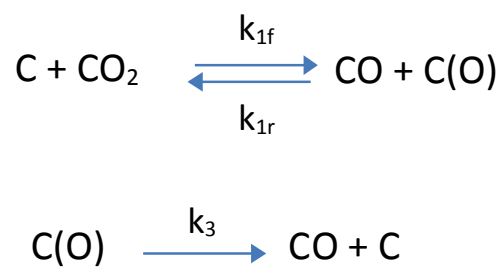

Eqn. 2

The Langmuir-Hinshelwood coefficients (K's) are related to the reaction rate constants (k's) through the following equations: 
Eqn. 3a. $\quad \mathrm{K}_{1}=\mathrm{k}_{1 \mathrm{fo}} * \exp \left(-\Delta \mathrm{H}_{1} /(\mathrm{R} * \mathrm{~T})\right)$

Eqn. 3b. $\quad \mathrm{K}_{2}=\mathrm{k}_{1 \mathrm{ro}} / \mathrm{k}_{30} * \exp \left(-\left(\Delta \mathrm{H}_{2}-\Delta \mathrm{H}_{3}\right) /(\mathrm{R} * \mathrm{~T})\right)$

Eqn. 3b. $\quad \mathrm{K}_{3}=\mathrm{k}_{1 \mathrm{fo}} / \mathrm{k}_{30} * \exp \left(-\left(\Delta \mathrm{H}_{1}-\Delta \mathrm{H}_{3}\right) /(\mathrm{R} * \mathrm{~T})\right)$

A paper by Hustad and Barrio on the Boudouard reaction of relatively pure graphitized Norwegian Birchwood char was found in the literature that provided the reaction rate constants and LangmuirHinshelwood coefficients with their activation energies, listed in Table I.

\begin{tabular}{|l|l|}
\hline $\begin{array}{l}\text { Hustad and Barrio Boudouard Reaction Rate } \\
\text { Constants }\end{array}$ & $\begin{array}{l}\text { Hustad and Barrio Boudouard Reaction Rate } \\
\text { Activation Energies }\end{array}$ \\
\hline $\mathrm{k}_{1 \mathrm{fo}}=1.30 / \mathrm{Pa}^{*} \mathrm{~s}$ & $\Delta \mathrm{H}_{1}=165 \mathrm{KJ} / \mathrm{mol}$ \\
\hline $\mathrm{k}_{1 \mathrm{ro}}=3.6 \times 10^{-6} / \mathrm{Pa}^{*} \mathrm{~s}$ & $\Delta \mathrm{H}_{2}=20.8 \mathrm{KJ} / \mathrm{mol}$ \\
\hline $\mathrm{k}_{3 \mathrm{o}}=3.23 \times 10^{7} / \mathrm{s}$ & $\Delta \mathrm{H}_{3}=236 \mathrm{KJ} / \mathrm{mol}$ \\
\hline Langmuir-Hinshelwood Coefficients & Langmuir-Hinshelwood Activation Energies \\
\hline $\mathrm{K}_{1 \mathrm{o}}=\mathrm{k}_{1 \mathrm{fo}}=1.30 / \mathrm{Pa}^{*} \mathrm{~s}$ & $\Delta \mathrm{H}_{1}=165 \mathrm{KJ} / \mathrm{mol}$ \\
\hline $\mathrm{K}_{2 \mathrm{o}}=\mathrm{k}_{1 \mathrm{ro}} / \mathrm{k}_{30}=1.11455 \times 10^{-13} / \mathrm{Pa}$ & $\Delta \mathrm{H}_{2}-\Delta \mathrm{H}_{3}=-215.2 \mathrm{KJ} / \mathrm{mol}$ \\
\hline $\mathrm{K}_{30}=\mathrm{k}_{1 \mathrm{fo}} / \mathrm{k}_{30}=4.02477 \times 10^{-08} / \mathrm{Pa}$ & $\Delta \mathrm{H}_{1}-\Delta \mathrm{H}_{3}=-71 \mathrm{KJ} / \mathrm{mol}$ \\
\hline
\end{tabular}

Table I Hustad and Barrio Boudouard Reaction Rate Kinetics Constants and Langmuir-Hinshelwood Coefficients

The most important gas reaction in the Martian environment is the oxidation reaction of FWPF C/C in the low partial pressure of oxygen. The literature contains numerous sets of data on the oxidation kinetics of uninhibited $\mathrm{C} / \mathrm{C}$ without a protective coating as a function of temperature. Each of these sets of experimental data show two regions of the oxidation reaction as shown in Figure1, an Arrenhius plot of the oxidation rate. The first region in the figure is chemical kinetics dominated with an activation energy of 80 to $170 \mathrm{~kJ} /$ mole up to a limiting temperature of $\sim 900^{\circ} \mathrm{C} / 1173 \mathrm{~K}$, when the dominant mechanism of oxidation changes to boundary layer mass transfer control. In this second region, the rate of reaction is dominated by the rate of gas diffusion of reactants and products through the boundary layer. The reaction rate in boundary layer diffusion control has a temperature dependence of $\mathrm{T}^{3 / 2}$ from the temperature dependence of the diffusion of the $\mathrm{O}_{2}, \mathrm{CO}_{2}$, and $\mathrm{CO}$ gas species in the Chapman- Enskog equation for gas diffusion coefficients.

The rate of oxidation of uninhibited, uncoated C/C like FWPF is shown in Figure 1, showing both regions of oxidation reaction kinetics control. The experimental data for the oxidation of $\mathrm{C} / \mathrm{C}$ in the literature is generally measured at an oxygen partial pressure of $0.21 \mathrm{~atm}$, atmospheric oxygen pressure. On this figure, the experimental oxidation kinetics data of carbon-carbon found in report by Meier et.al. (3) are plotted along with Arrenhius regression fit equation of this data in this region of control (green line). A diffusion controlled, boundary layer kinetics curve with a $\mathrm{T}^{3 / 2}$ temperature dependence (pink line) is also shown at lower levels of the inverse temperature parameter (higher temperatures). 


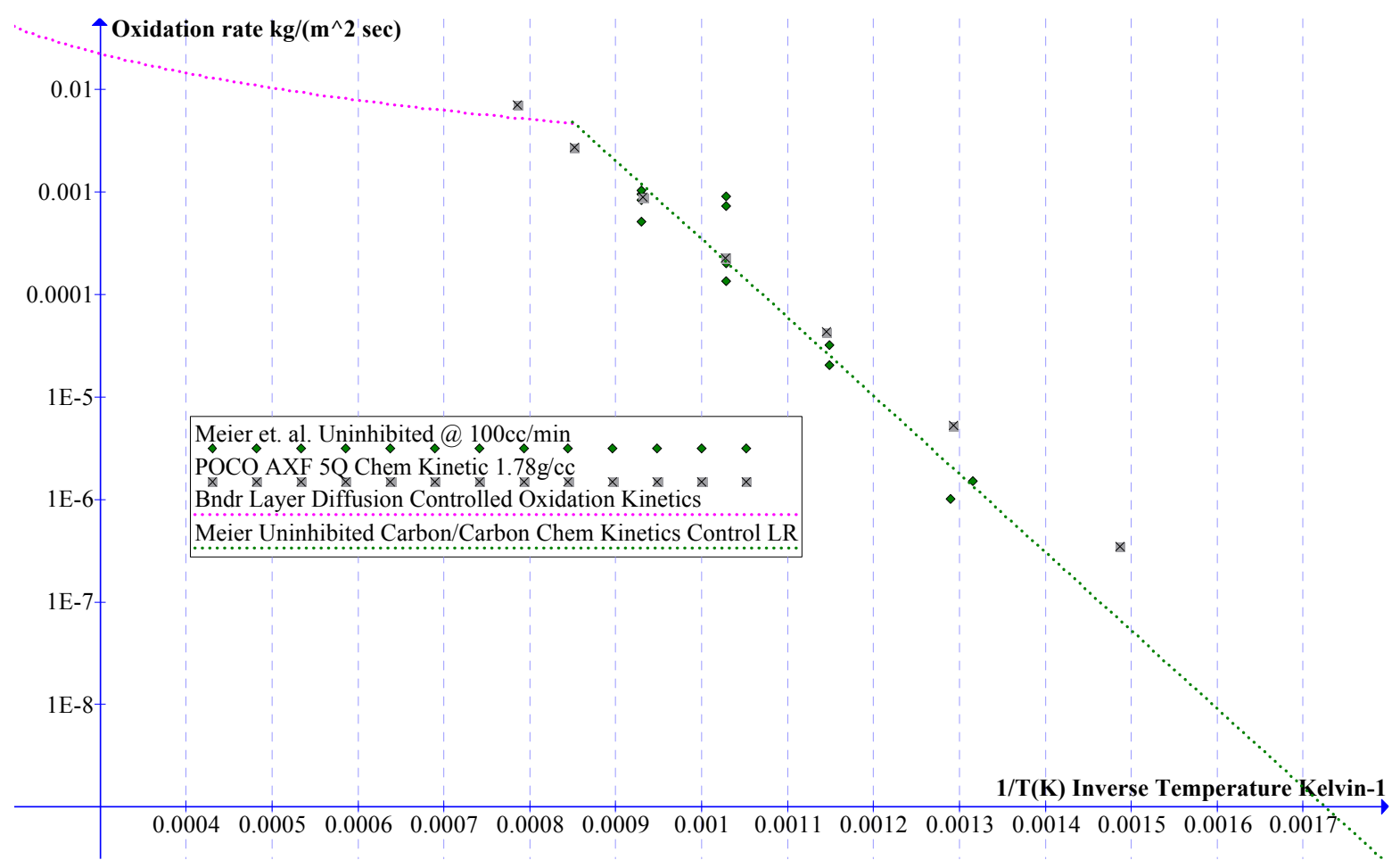

Figure 1 Arrenhius Plot of the Oxidation of Uninhibited Carbon- Carbon at 0.21 atm Oxygen Partial Pressure

The FWPF chemical reaction model uses a $\mathrm{P}_{2}{ }^{n}$ oxygen partial pressure dependence for the reaction rate as shown in Equation 4. The exponent $\mathrm{n}$ used in Equation 4 in the model was 0.9. Due to the partial pressure dependence of the oxidation rate, the rate on the surface of Mars with an oxygen partial pressure of $1.04 \mathrm{~Pa}$ is a factor of 14,000 less than those shown on Figure 1 at $0.21 \mathrm{~atm}$.

The rates of reaction from the Boudouard and $\mathrm{C} / \mathrm{C}$ oxidation kinetics equations are added together in the computer model to obtain the overall rate of reaction. The overall reaction rate of the FWPF C/C in the model is the sum of the Boudouard reaction rate (Eqn. 2) with the oxidation reaction rate.

\section{Eqn. 4}

Equation 5 defines the degree of reaction parameter for calculating the amount of a chemical reaction: Eqn. 5

where $\Delta \mathrm{w}$ is the mass lost by the FWPF due to chemical reaction. The first order differential equation that governs the degree of reaction of a chemical reaction is:

Eqn. 6

where: $\varepsilon$ is the porosity of the FWPF carbon-carbon

$A(t)$ is the surface area of the aeroshell as a function of time

$\mathrm{m}$ is shape parameter of the particle being reacted

$\mathrm{m}=1$; Volume Reaction Model

$\mathrm{m}=1 / 2$; cylindrical particles like graphite fibers

$\mathrm{m}=2 / 3$; spherical particles

$\mathrm{m}=0$; flat plate particles 
Rearrangement of Equation 6 followed by integration yields:

Eqn. 7

Integration and algebraic rearrangement results in the final forms of the degree of reaction equation:

Eqn. $8 \mathrm{a}$

where $m \neq 1$

Eqn. $8 \mathrm{~b}$

where $\mathrm{m}=1$

FWPF carbon-carbon is a porous material with a large amount of internal surface area for chemical reaction. The Opila report used to benchmark this reaction model, measured the internal surface area in the FWPF samples to be $0.561 \mathrm{~m}^{2} / \mathrm{g}$ with a BET gas absorption technique. This factor was used within the reaction model to calculate the initial internal surface area of the FWPF aeroshell. Including the internal surface area in a carbon-carbon chemical reaction model is significant because it is 335,000 times larger than the aeroshell's surface area and therefore controls the amount of chemical reaction that occurs.

It should be noted that this approximation assumes that the entire internal surface area is fully available for reaction. The probability that a hot $\mathrm{CO}_{2}$ or $\mathrm{O}_{2}$ molecule will reach the inner most parts of the GPHS module before it reacts is low. Thus, the actual area "available" for reaction with $\mathrm{CO}_{2}$ and/or $\mathrm{O}_{2}$ is somewhere between the external and the internal surface area of the aeroshell. Since the actual available surface area will need to be determined experimentally, this analysis model-based report uses the more conservative assumption and calculates the rate based on the total internal + external surface area, with an experimentally determined calibration coefficient. An actual reaction with a GPHS module under the given circumstances is expected to be slower, but the exact rate cannot be determined without more experimental data.

Opila's report also showed that the internal surface area increased by a factor of 6.45 during the chemical reaction experiment. This surface area increase is caused by the combined $\mathrm{CO}_{2}$ and $\mathrm{O}_{2}$ chemical reactions at the surfaces of the internal pores and at the fiber-matrix interface of the carbon/carbon. As shown in Equation 8 the increased internal surface area increases the degree of reaction at a given time of reaction. The internal surface area increase during the chemical reaction of FWPF was modelled as an S shaped cumulative Erlang probability density function. This function was chosen to model the internal area increase because it has an-initiation phase where the internal area growth is slow, a middle phase where the area increases rapidly and a final phase where the opportunity for further surface area growth is inhibited. This function was chosen because it models the growth of internal surface area better than a linear internal area increase would. 
The integral of the internal surface area increase in Equation 8 is:

Eqn. 9

where the magnitude of the surface area increase during the reaction is $\Delta \mathrm{A}$ and the area increase function was modelled as a cumulative Erlang probability density function. Combining Equations 8 and 9 results in the following:

Eqn. 10

where the integral is the time integral of the cumulative Erlang distribution

\section{function which is:}

Eqn. 11

Where $s$ is the Erlang distribution function shape parameter and $\lambda$ is the time parameter. An Erlang function series of shape parameter $\mathrm{s}=3$ separates into three terms that are integrated between the limits of 0 and $\mathrm{t}$. Dividing the integral by the time interval (t-0) yields the average surface area of the FWPF, shown in Equation 12.

Eqn. 12

Equation 12 is applicable for calculating the average area as a function of time for an Erlang cumulative distribution function with a shape parameter $\mathrm{s}=3$. The final version of the degree of reaction equation foillows

Eqn. 13

\subsection{Benchmarking of the FWPF Chemical Reaction Kinetics Model for Martian Environment}

The FWPF chemical reaction model was benchmarked using the Opila's experimental chemical reaction test data (1) in a simulated Martian environment to increase the validity of the model's predicted mass loss rate. The benchmarking is necessary because not all of the open porosity internal surface area measured for FWPF deep within the aeroshell has the opportunity to chemically react at a point in time. The comparison of the benchmarked reaction model with the Opila experimental data are shown in Figure 2. The Opila data was measured in experiments performed in a pure $800 \mathrm{~Pa} \mathrm{CO}_{2}$ gas environment and in an environment containing $800 \mathrm{~Pa} \mathrm{CO}_{2}$ and $0.8 \mathrm{~Pa} \mathrm{O}_{2}$ partial pressure, replicating the gas chemistry on the surface of Mars. The experimental data curves show that $\sim 70 \%$ of the mass loss of the FWPF is due to the 
addition to the environment of $0.8 \mathrm{~Pa}$ oxygen gas. The FWPF reaction rate model would not agree with Opila's experimental data if the surface area is held constant in the model, equal to the original surface area of Opila's reaction sample. The increase of the model's internal surface area during the reaction with the inclusion of the cumulative Erlang function caused the model and the experimental model to agree.

In the benchmarking task, the objective was to get the model to match Opila's data throughout the entire timeframe of the experiment. This was done by adjusting the Boudouard and Oxidation reaction rates with calibration factors and also-the shape parameter (s) and the time constant $(\lambda)$ of the cumulative Erlang function surface area increase to match the model's output to Opila's FWPF C/C experimental reaction weight loss data. The time constant, $\lambda$ controls how rapidly the cumulative Erlang function goes from zero to one and the shape parameter, s controls how much $\mathrm{S}$ shape is in the curve. The blue and purple lines in Figure 2 show a comparison of the best fit FWPF reaction rate model with Opila's experimental data. The "best fit" parameters for these curves are shown in Table I.

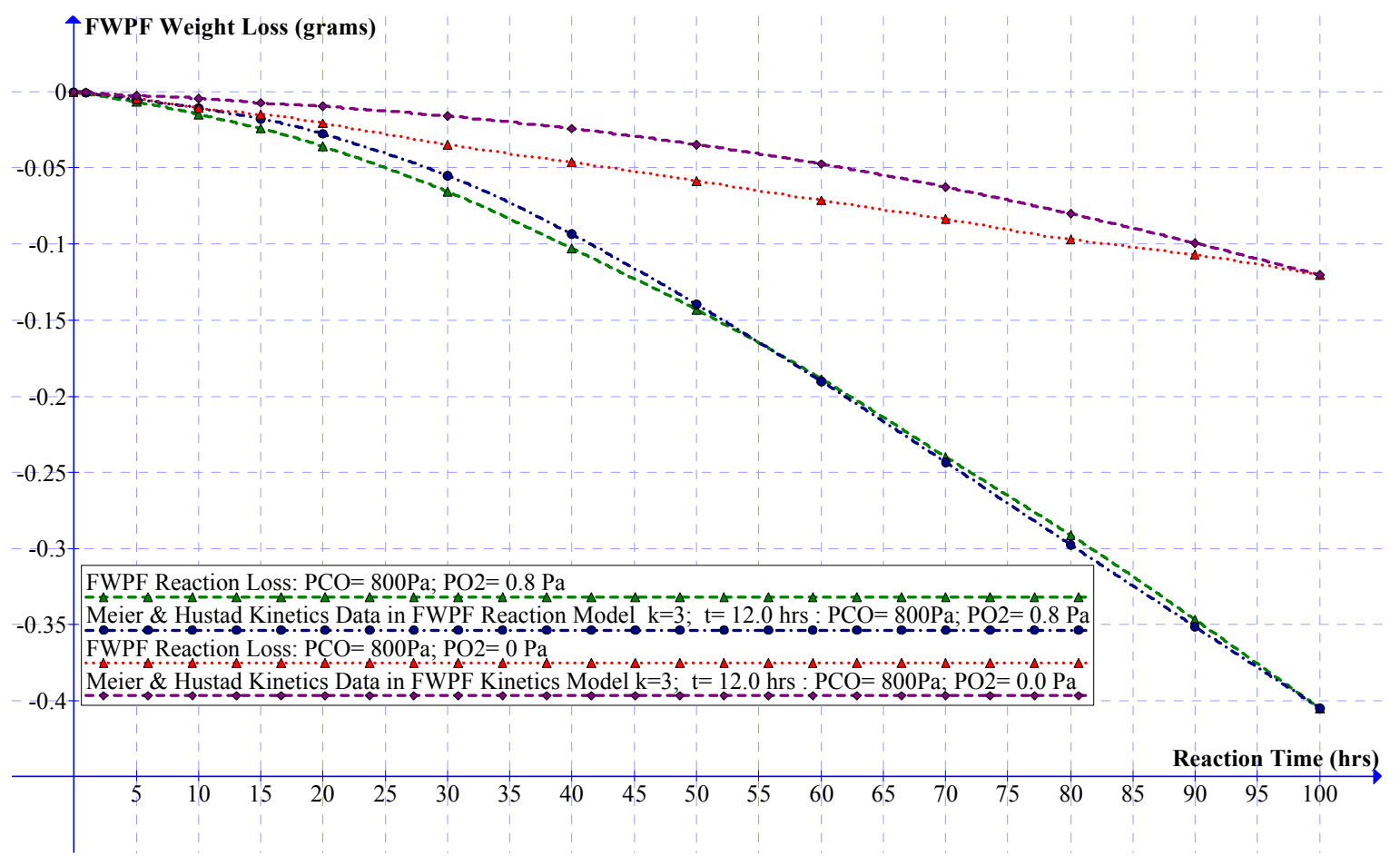

Figure 2 Comparison of the FWPF Reaction Model with "Best Fit" Parameters to Opila Experimental Reaction Weight Loss Data at $900{ }^{\circ} \mathrm{C}$ and $800 \mathrm{~Pa} \mathrm{CO}_{2}$ and $0.8 \mathrm{~Pa} \mathrm{O}_{2}$ Partial Pressures Simulating a Martian Environment 


\begin{tabular}{|l|l|l|l|l|l|}
\hline $\begin{array}{l}\text { Boudouard } \\
\text { Reaction } \\
\text { Calibration } \\
\text { Parameter }\end{array}$ & $\begin{array}{l}\text { Oxidation } \\
\text { Reaction } \\
\text { Calibration } \\
\text { Parameter }\end{array}$ & $\begin{array}{l}\text { Calibration } \\
\text { Parameter for } \\
\text { Erlang CDF } \\
\text { Rate Constant } \\
\mathrm{kg} /\left(\mathrm{m}^{2 *} \mathrm{sec}\right)\end{array}$ & $\begin{array}{l}\text { Oxidation } \\
\text { Reaction } \\
\text { Partial } \\
\text { Pressure } \\
\text { Exponent } \mathrm{n}\end{array}$ & $\begin{array}{l}\text { Erlang CDF } \\
\text { Shape } \\
\text { Parameter k }\end{array}$ & $\begin{array}{l}\text { Erlang CDF } \\
\text { Rate Constant } \\
\lambda(\mathrm{hrs})\end{array}$ \\
\hline $1.419 \times 10^{-6}$ & $3.424 \times 10^{-4}$ & $3.454 \times 10^{-10}$ & 0.9 & 3 & $1 / 12.0 \mathrm{hrs}$ \\
\hline
\end{tabular}

Table II "Best Fit" Parameters for the GPHS FWPF Reaction Model to Fit Opila Experimental Reaction Weight Loss Data at $900 \mathrm{C}$ with $800 \mathrm{~Pa} \mathrm{CO}_{2}$ and $0.8 \mathrm{~Pa} \mathrm{O}_{2}$ Partial Pressures

The benchmarked FWPF reaction model was run in the gas environment of Mars at temperatures of 300 ${ }^{\circ} \mathrm{C} / 573 \mathrm{~K}$ to $1000{ }^{\circ} \mathrm{C} / 1273 \mathrm{~K}$ for time frames of 0.25 to 10 years to calculate the amount of reaction of the aeroshell of an RPS designed to be open to a flowing Martian gas environment. The intent of this analysis is to determine the temperature limit of the aeroshell in the new GPHS-RTG that can withstand the Martian environment with a mass loss fraction of $10 \%$. We have defined the loss of $10 \%$ of the carbon on both the surface and internally within the pores as the limit of failure where the aeroshell will being unable to transfer heat effectively, its primary function on the surface of Mars.

The FWPF reaction model uses the Hustad and Barrio Boudouard reaction Langmuir-Hinshelwood constants. Another set of Langmuir-Hinshelwood constants for the Boudouard reaction of pure graphite were measured by Walker and Strange. Their constants were not used in the final version of the model because the units of measurement in their paper were not straight-forward and required conversion with the universal gas law to moles $/ \mathrm{sec}$ from $\mathrm{cm}^{3} / \mathrm{sec}$. When their constants were converted, substituted into the model and also benchmarked with the Opila data, the model with Walker and Strange's constants calculated nearly identical degrees of reaction for FWPF as those from the model using the Hustad and Barrio constants, plotted in Figures $3 \mathrm{a}$ and $3 \mathrm{~b}$. This is an indication that the kinetics coefficients for the Boudouard reaction on different types of carbon have some consistency.

The inclusion of $0.640 \mathrm{~Pa}$ carbon monoxide partial pressure in the gas environment using the LangmuirHinshelwood kinetic equation has the effect of retarding the Boudouard reaction by $-0.04 \%$ at $900{ }^{\circ} \mathrm{C}$, a very slight effect. The use of this kinetic equation with the retarding effect of carbon monoxide would be more important in a model with a limited amount of mass transport of Martian gases into the RPS. The addition of the $1.04 \mathrm{~Pa}$ oxygen to the gas environment increased the overall rate of reaction by $+82.2 \%$, a very substantial increase. 


\subsection{Calculation of Degree of Reaction of FWPF Aeroshell with Chemical Reaction Kinetics Model in Martian Environment}

The degree of reaction curves with reaction time at temperatures from 300 to $900{ }^{\circ} \mathrm{C}$ in the Martian environment are shown in Figures 3a and 3b. In Figure 3a the degree of reaction initially increases rapidly with the time of reaction then asymptotically approaches 1 , where the entire aeroshell would be completely consumed at long reaction times. The black line shown on this figure, is at a degree of reaction of 0.1 , the defined upper acceptable limit of the degree of reaction. These figures also show that model's predicted degrees of reaction increase rapidly with increased aeroshell temperature, due the thermally activated nature of all the kinetic coefficients for both reactions used in the model.

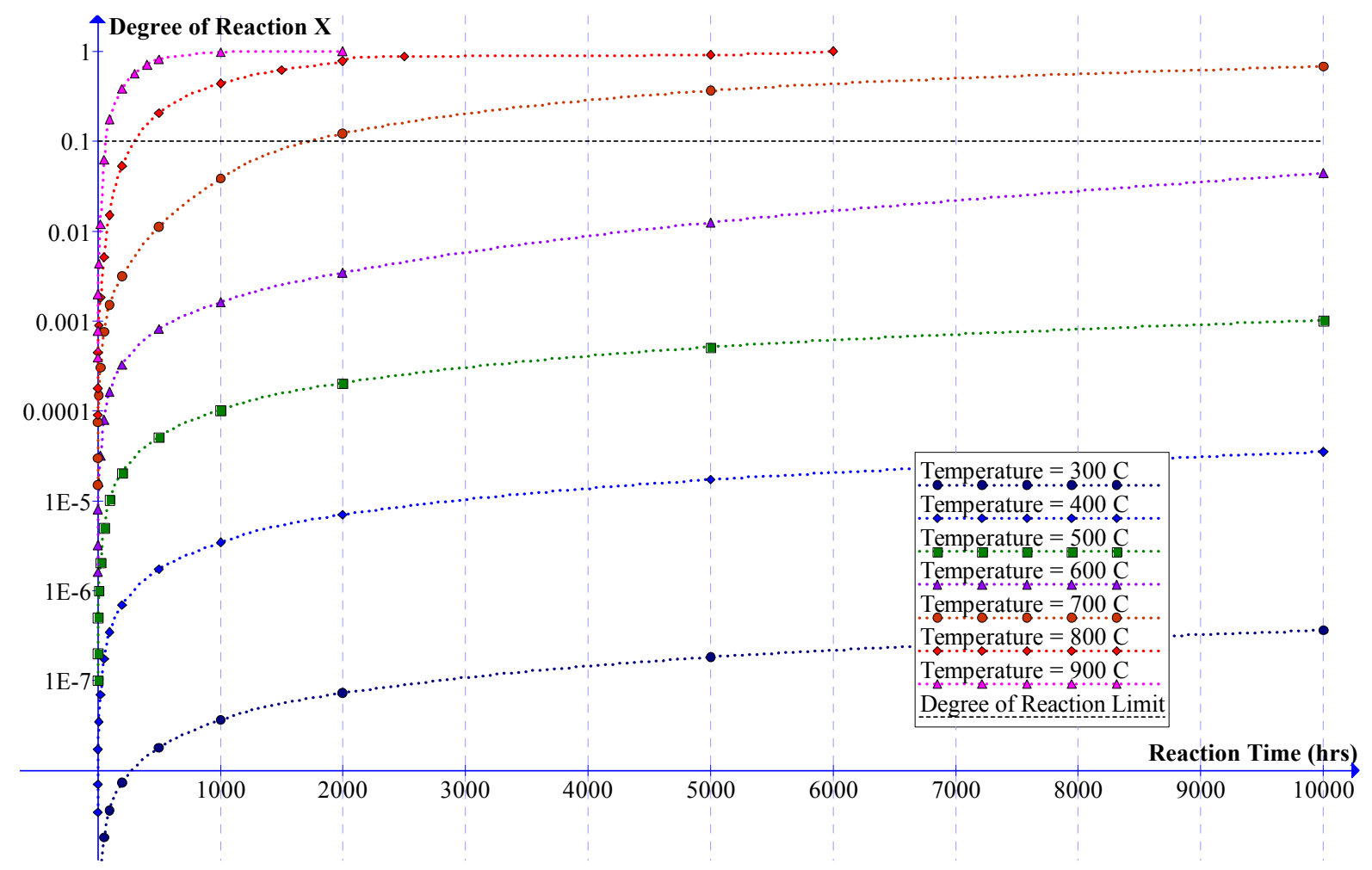

Figure 3a Predicted Degrees of Reaction from Benchmarked FWPF Reaction Model at Temperatures from $300{ }^{\circ} \mathrm{C}$ to $900{ }^{\circ} \mathrm{C}$ at $763 \mathrm{~Pa} \mathrm{CO}_{2}, 1.04 \mathrm{~Pa} \mathrm{O}_{2}$ and $0.64 \mathrm{PaCO}$ Partial Pressures, Simulating a Martian Environment; Semi-logarithmic Plot 


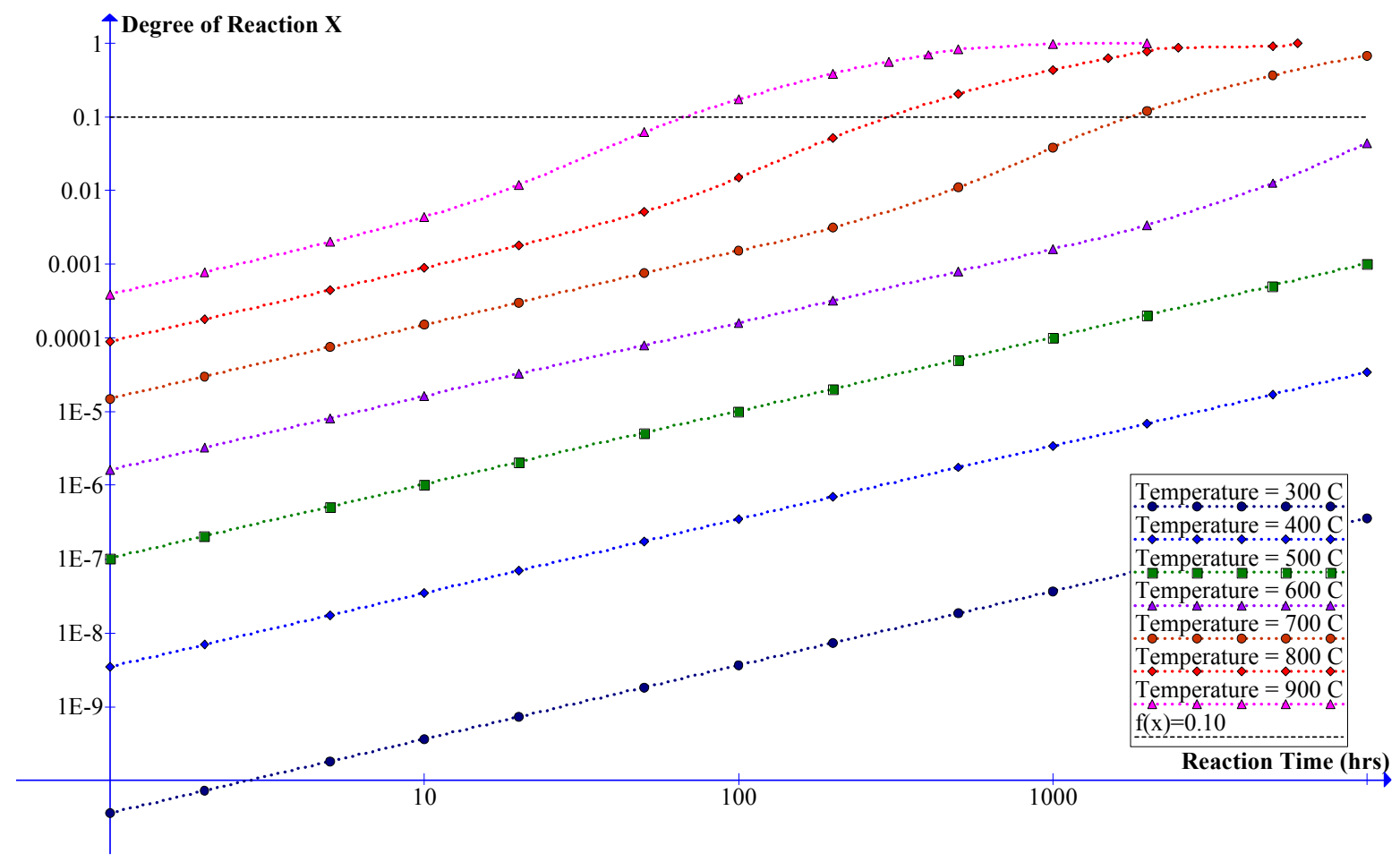

Figure $3 \mathrm{~b}$ Predicted Degrees of Reaction from the Benchmarked FWPF Reaction Model at Temperatures from $300{ }^{\circ} \mathrm{C}$ to $900{ }^{\circ} \mathrm{C}$ at $763 \mathrm{~Pa} \mathrm{CO}_{2}, 1.04 \mathrm{~Pa} \mathrm{O}_{2}$ and $0.64 \mathrm{PaCO}$ Partial Pressures, Simulating a Martian Environment; Log-Log Plot

Figure 4 shows the degree of reaction on the FWPF aeroshell as a function of the temperature of the aeroshell within a new GPHS-RTG RPS that is open to a flowing Martian gas environment. This figure shows that the aeroshell will reach its 0.1 degree of reaction limit after 10 years of exposure at an aeroshell temperature of 810 Kelvin or $537^{\circ} \mathrm{C}$. 


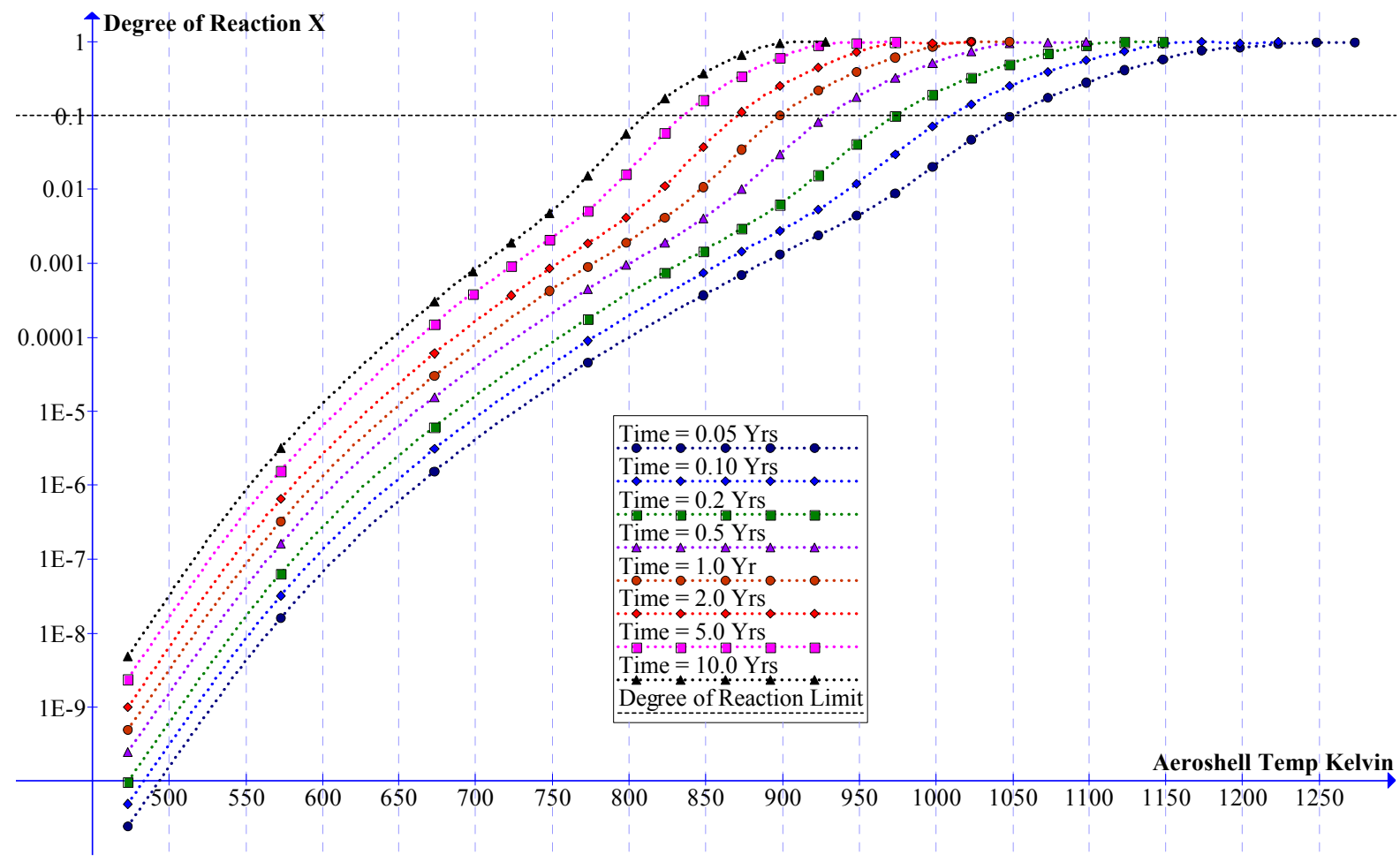

Figure 4 Predicted FWPF Degrees of Reaction from the Benchmarked FWPF Reaction Model at Martian Mission Lives from 0.05 to 10 years as a Function of Aeroshell Temperature in a Martian Environment

Table II shows the upper temperature limitation for the aeroshell as a function of mission life for a new RPS that is open to a flowing Martian gas environment. At these temperatures, the upper acceptable limit of the degree of reaction of 0.1 is attained at the end of the mission life. This table shows that an open RPS creates a trade-off of the aeroshell temperature with the intended length of mission on Mars. For example, an RPS with a five-year intended mission life on Mars has a maximum aeroshell temperature of $835 \mathrm{~K} / 562{ }^{\circ} \mathrm{C}$. Increasing the mission life to ten years reduces the temperature to $810 \mathrm{~K} /$ $527^{\circ} \mathrm{C}$. The data from Table II are plotted on Figure 6, showing the maximum aeroshell temperature is a power law decay function regression fit of the design mission life on Mars.

All of the chemical reaction kinetics coefficients within the model are thermally activated, therefore the aeroshell reaction rate is strongly dependent on temperature. At 970 Kelvin (7), the aeroshell would attain its 0.1 degree of reaction limitation in 0.22 years / 81 days, while at 1343 Kelvin (6), the reaction limitation would occur in only 0.375 days $/ 9 \mathrm{hrs}$. 


\begin{tabular}{|l|l|}
\hline Mission Life on Mars & Aeroshell Upper Temperature Limit \\
\hline 0.05 years & 1049.2 Kelvin \\
\hline 0.1 years & 1009.8 Kelvin \\
\hline 0.2 years & 973.3 Kelvin \\
\hline 0.5 years & 929.2 Kelvin \\
\hline 1.0 years & 898.7 Kelvin \\
\hline 2.0 years & 870.3 Kelvin \\
\hline 5.0 years & 835.4 Kelvin \\
\hline 10.0 years & 810.3 Kelvin \\
\hline 15.0 years & 795.9 Kelvin \\
\hline
\end{tabular}

Table III GPHS FWPF Aeroshell Upper Temperature Limits as a Function of the Mission Life of an RPS Open to the Martian Environment.

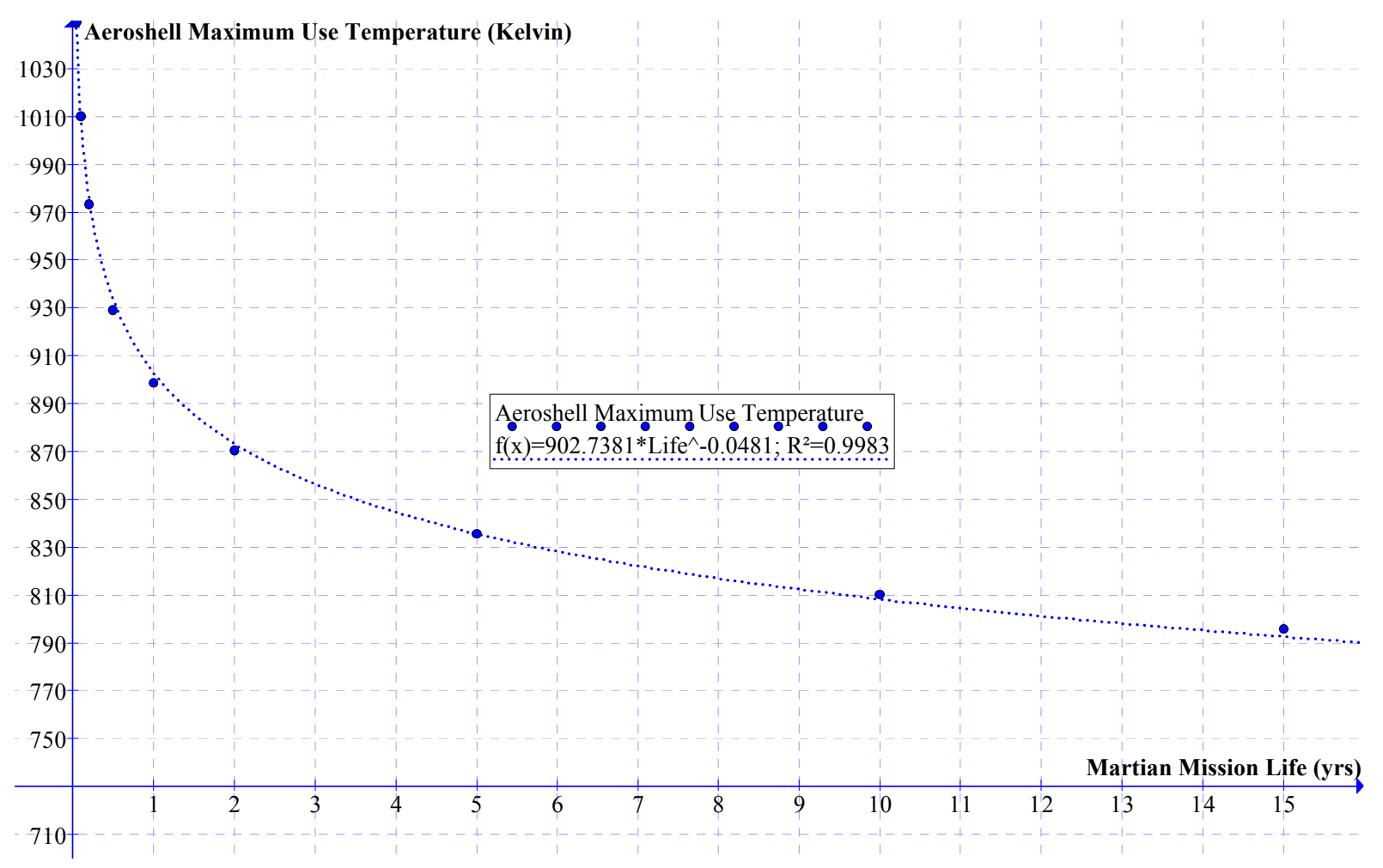

Figure 5 Predicted GPHS FWPF Aeroshell Upper Temperature Limit as a Function of the Mission Life of an RPS Open to the Martian Environment.

\subsection{Conclusion}

The conclusion to be drawn from the output of chemical reaction model developed in this report is environmental chemical reactions prevent an RPS-that is open to the Martian environment from achieving the desired mission life at aeroshell temperatures in excess of 850 Kelvin. Acceptable mission lives on Mars of 5 to 10 years may be attained at lower aeroshell temperatures of 835 to 810 Kelvin. 
Some fundamental assumptions used in this analysis and physical limitations of the aeroshell will not be valid as the total mass loss approaches $100 \%$. As a result, extrapolating the conclusions in this report far beyond the $10 \%$ failure limit that was used is not advised.

Data from this analysis is only valid when considering a fully open RPS design. A design that includes a more restrictive flow of gases into, and out of, the RPS would slow down the reaction rate and extend the life of the FWPF. Another chemical reaction model analysis that takes into account the flow or leakage of gas reactants and products will be required before any conclusions could be drawn regarding the lifetime of an RPS with restricted gas flow on the surface of Mars.

\subsection{References}

(1) E.J Opila, "Oxidation of Fine Weave Pierced Fabric Graphite in a Simulated Mars Environment at Temperatures Between 700 and $900^{\circ} \mathrm{C}^{\prime}$, NASA/TM-2006-214404, Oct. 2006, NASA Glenn Research Center Report, Cleveland Ohio,

(2) M Barrio and J. E.Hustad, "CO 2 Gasification of Birch Char and the Effect of CO Inhibition on the Calculation of Chemical Kinetics”, Progress in Thermochemical Biomass Conversion, April 2008, pp. 47-60

(3) J Cullinan, J. Schaeffer, E.A. Gulbransen, G.H. Meier, and F.S. Pettit, "Oxidation of CarbonCarbon Composites and Coatings and Coatings on These Materials", Figure 24, AFOSR-TR-891643, Sept. 30, 1989, Air Force Office of Scientific Research Report, Bolling AFB, District of Columbia

(4) J. F. Strange and P.L. Walker, "Carbon Dioxide Reaction: Langmuir-Hinshelwood Kinetics at Intermediate Pressures”, Carbon, Vol. 14, (1976) pp. 345-350, May. 25, 1976

(5) G.H. Rinehart, "Design Characteristics and Fabrication of Radioisotope Heat Sources for Space Missions", Progress in Nuclear Energy, Vol. 39, (2001) No. 3-4, pp. 305-319

(6) M.S. El-Genk, T.M. Schreiner, and J.J. Breedlove, "Thermal Analyses of Heat Source Assembly for a Dual Loop, Turbo-Brayton Radioisotope Power System", Thermal Science and Engineering Progress, Vol. 10, (2019) pp. 82-91

(7) H. Novarian, "MSL MMRTG Thermal Event Model", ANALYTIX Corporation Presentation to Orbital Sciences Corporation, July 3, 2008 
Page intentionally left blank 